\title{
Impact of Position on Efficacy of Caudal Epidural Injection for Low Back Pain and Radicular Leg Pain Due to Central Spinal Stenosis and Lumbar Disc Hernia
}

\author{
Idiris Altun, M.D., Kasım Zafer Yuksel, M.D. \\ Department of Neurosurgery, Kahramanmaras Sutcu Imam University Medical Faculty, Kahramanmaras, Turkey
}

Objective : This study was performed to evaluate and compare the efficacies of caudal epidural injections performed at prone and lateral decubitus positions.

Methods : A total of 120 patients suffering from low back pain and radicular leg pain were included and patients were randomly distributed into 2 groups according to the position during injection. In Group 1 ( $n=60 ; 32$ women, 28 men), caudal epidural injection was performed at prone position, whereas it was implemented at lateral decubitus position in Group 2 ( $n=60 ; 33$ women, 27 men). Visual analogue scale, Oswestry Disability Index (ODI), walking tolerance (WT) and standing tolerance (ST) were compared in 2 groups before and after injection.

Results : In Group 1, ODI values were higher at 30th minute ( $p=0.007)$, 3rd week $(p=0.043)$ and 6th month ( $p=0.013)$. In Group 1, ODI, VAS and ST values were improved significantly at all follow-up periods compared to initial values. In Group 1, WT scores were better than initial values at 30th minute, 3rd week and 3rd month. In Group 2, ODI scores at 30th minute, 3rd week, 3rd month and 6th month were improved while VAS and ST scores were improved at all periods after injection. WT scores were better at 30th minute, 3rd week and 3rd month compared to initial WT scores.

Conclusion : Our results indicated that application of injection procedure at lateral decubitus position allowing a more concentrated local distribution may provide better relief of pain.

Key Words : Low back pain · Lumbalgia · Treatment · Caudal epidural injection · Position.

\section{INTRODUCTION}

Caudal epidural injections are commonly and effectively being used in the treatment of low back pain and radicular leg pain. The compression and inflammation of the nerve root may lead to pain and steroids may alleviate pain and other symptoms by inhibition of the inflammatory reaction ${ }^{8)}$. The caudal epidural injections are administration of steroids locally to the affected nerve roots directly in order to provide a quicker and more effective relief of pain. Even though caudal epidural injections are not as selective as transforaminal injections, they are supposed to be superior to non-steroidal anti-

- Received : May 9, 2016 •Revised : December 5, 2016 •Accepted : December 9, 2016

- Address for reprints : Idiris Altun, M.D.

Department of Neurosurgery, Kahramanmaras Sutcu Imam University Medical Faculty, Kahramanmaras, Turkey

Tel : +90-3442803434, Fax : +90-3442803409, E-mail : idrisaltun46@hotmail.com

This is an Open Access article distributed under the terms of the Creative Commons Attribution Non-Commercial License (http://creativecommons.org/licenses/by-nc/4.0) which permits unrestricted non-commercial use, distribution, and reproduction in any medium, provided the original work is properly cited. 
inflammatory medications in the treatment of low back pain linked with radiculopathy ${ }^{4}$. Moreover, combination of a steroid and a long-acting local anesthetic like bupivacaine is supposed to have additional beneficial therapeutic effects in these therapeutic procedures ${ }^{8)}$. Effectiveness of caudal epidural injections has been investigated in several publications and controversial results have been reported ${ }^{1,9)}$.

During caudal epidural injection, positioning may enhance accurate placement of the needle and may improve therapeutic outcomes by causing a better distribution of injectate onto the target tissues. It has been reported that lateral decubitus positioning after a caudal epidural injection may improve outcome by enhancing sensory block similar to that in spinal anesthesia $^{8)}$. However, impact of position during caudal epidural injection on the outcome has not been reviewed thoroughly in the medical literature yet. Owing to the effect of gravity during positioning, distribution of solution may be altered and therefore, lateral decubitus positioning on the dependent side during injection may yield more favorable results in treatment of low back pain and radicular leg pain.

The objective of the present study was to evaluate the impact of positioning of the patient during caudal epidural injection on therapeutic and functional outcomes of patients suffering from low back pain and radicular leg pain.

\section{MATERIALS AND METHODS}

\section{Study design}

This prospective, controlled, randomized study was implemented in the neurosurgery department of our institution subsequent to the approval of the local Institutional Review Board (2014/17-05). Written informed consent was provided from all patients for participation in this study.

This trial was performed on 160 patients admitting to the outpatient department of our institution due to low back pain and radicular leg pain. Patients were diagnosed either with central spinal stenosis (CSS) $(n=80)$ or lumbar disc hernia $(\mathrm{LDH})(\mathrm{n}=80)$. All patients were informed about the study and they were blinded to grouping data. Patients were randomly allocated in 2 groups using a computer program to determine the position to be used during caudal epidural injection. Homogeneous subgroups were constituted for injection at prone or lateral decubitus positions. Only one of the authors (ZY) was aware of the grouping data and all data were gathered by the medical team blinded to grouping data.

Inclusion criteria for both CSS and LDH groups were age $\geq 18$ years, willingness for participation, complaints of low back pain, radicular leg pain and/or functional restriction due to pain for longer than 6 months, lack of medical treatment and physical medication during last 6 weeks and CSS or LDH confirmed via magnetic resonance imaging (MRI). Exclusion criteria were polyneuropathy, cauda equina, congenital stenosis, foraminal stenosis, history of epidural steroid injection within preceding 6 months and bupivacaine allergy.

\section{Outcome parameters}

The numeric rating scale (NRS), Oswestry Disability Index (ODI), walking tolerance (WT) and standing tolerance (ST) before and 30 minutes, 3 weeks, 3 months, 6 months and 12 months after injection were noted and compared in groups receiving the injectate at lateral decubitus or prone positions. Parameters under investigation were comprised of descriptive variables such as age and gender, as well as NRS, ODI, WT and ST.

Patients were evaluated prior to the caudal epidural injection by a single observer using an 11-point numeric rating scale (NRS) and the ODI grading the pain and functional restriction in this series ${ }^{6,10)}$. The numeric rating scale (NRS) consisted of a 10 point scale, with one end defined as "no pain" and the other end as "excruciating pain". Patients were asked to mark on the line to reflect the amount of pain they experience at a particular time. Oswestry Disability Index is a questionnaire used to assess functional restriction linked with low back pain ${ }^{6)}$.

\section{Injection procedure}

Epidural injections were made at the ambulatory care center under fluoroscopic guidance. Following the injections, patients were instructed to return to their normal activities on the same day. The technique was standardized in all procedures and patients were held in the lateral decubitus or prone positions on the radiology table. A wedge shaped pillow was placed under the hips or pelvis to achieve the desired position. The sacrococcygeal area was cleansed using an iodine-based antiseptic solution and an alcohol solution. The physician used the sterile gloved middle finger of the dominant hand to localize the tip of the coccyx through palpation. By using a 
fluoroscope (OEC Compact 7600 Salt Lake City, UT, USA), a 22-gauge, $3.5 \mathrm{inch} / 90 \mathrm{~mm}$ spinal needle (Quincke type point, Spinocan, Becton Dickinson, Franklin Lakes, NJ, USA) was introduced to the midline of the sacral hiatus and a lateral fluoroscopic view was used to confirm the needle was appropriately in the caudal epidural space. Aspirations were routinely performed. If negative for aspirate, Isovue M-300 (iopamidol injection Bracco Diagnostic, Princeton, NJ, USA) $2 \mathrm{~mL}$ was instilled to confirm epidural flow of the injectate and to rule out intravascular, intrathecal and/or soft tissue infiltration. The total injectate was $14 \mathrm{~mL}$ including contrast. All patients were with pulse oximetry, blood pressure and electrocardiography during and after the procedure. Patients had been transferred to the recovery unit for 40 minutes. Before discharge, patients were seen by the medical team consisting of the physician who performed the injection.

Patients were maintained at the same position for $10 \mathrm{~min}$ utes following injection. Nineteen patients in CSS group and 20 patients in LDH group were lost to follow-up and they were excluded from the study. Thus, a total of 121 patients (61 cases with CSS and 60 cases with LDH) were included in this trial. Radiologic evaluation was made by a neuroradiologist having an experience of 10 years in spinal MRI. Grading of central spinal stenosis was made as minor ( $\geq 13 \mathrm{~mm}$ ), moderate (11-13 $\mathrm{mm})$ and severe $(<11 \mathrm{~mm})$ as reported by Schizas et al. ${ }^{14}$.

Injections were performed under fluoroscopic guidance by the same experienced neurosurgeon (IA) who was blinded to the group data. The technique for caudal epidural injection is shown in Fig. 1. The injectate included $10 \mathrm{~mL}$ of normal saline, $10 \mathrm{~mL}$ of $0.5 \%$ bupivacaine and $40 \mathrm{mg}$ methylprednisolone as described in the previous publications ${ }^{8)}$.

Walking tolerance and standing tolerance have been used as measures of outcome in accordance with previous relevant literature $^{2,3,13}$. Walking tolerance was assessed in terms of distance and duration, while standing tolerance was evaluated with respect to duration only.

\section{Statistical analysis}

Data were analyzed using the IBM Statistical Package for Social Sciences (SPSS) software version 20.0 for Windows (SPSS Inc., Chicago, IL, USA). Normal distribution of continuous variables was evaluated with Kolmogorov Smirnov test. Parametric tests were used for variables distributed normally, while non-parametric tests were utilized for variables without

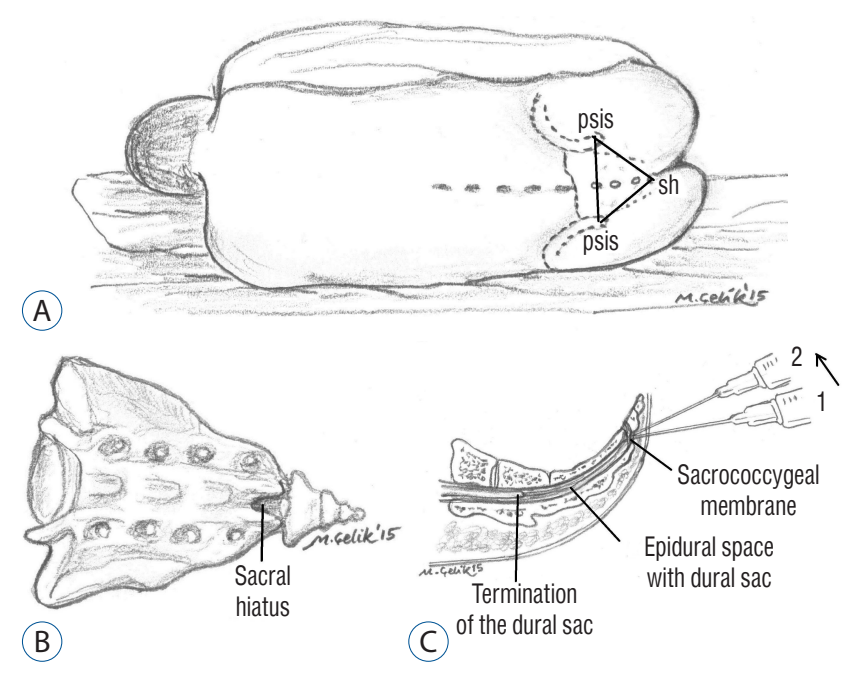

Fig. 1. The technique for caudal epidural injection. psis : posterior superior iliac spine, sh : sacral hiatus.

normal distribution. Two independent groups were compared by means of Independent-Samples $\mathrm{T}$ test and Mann-Whitney $\mathrm{U}$ test. Paired-Samples $\mathrm{t}$ test and Wilcoxon test were used for comparing two dependent groups. Continuous variables are presented as mean \pm standard deviation or median-interquartile range. Confidence interval was $95 \%$ and differences associated with a $p$ value less than 0.05 were considered as statistically significant.

\section{RESULTS}

Group $1(\mathrm{n}=60)$ consisted of 32 women and 28 men with an average age of $58.52 \pm 15.76$, while Group $2(n=60)$ was composed of 33 women and 27 men (average age : $58.57 \pm 15.37$ ). In Group 1, distribution of injection solution was fair for both sides (Fig. 2). In Group 2, the injection solution was more concentrated at the bottom in lateral decubitus position owing to the effect of gravity (Fig. 3).

Results of ODI displayed normal distribution and they were expressed as mean \pm standard deviation. In contrary, results of NRS, ST and WT did not have normal distribution and they were presented as median-interquartile range. As demonstrated in Table 1, analysis of our data indicated that ODI values in Group 1 were higher at 30 th minute $(p=0.007)$, 3rd week ( $p=0.043)$ and 6th month $(p=0.013)$. In terms of NRS, remarkable differences were observed between two groups at 30th 


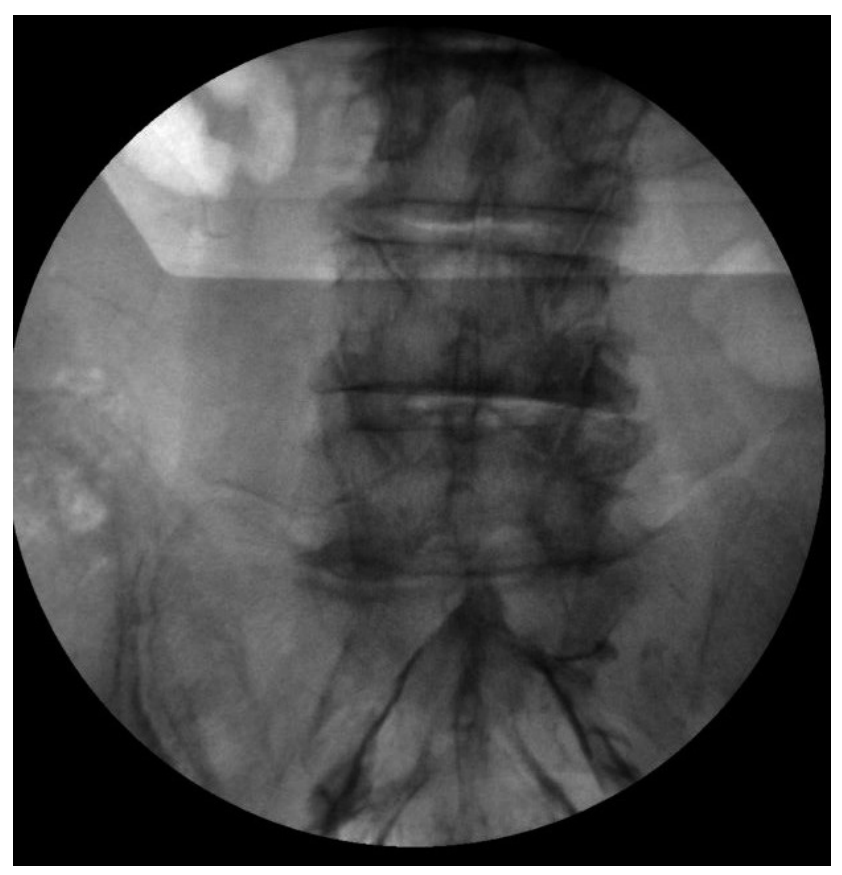

Fig. 2. Image demonstrating distribution of injection solution was fair for both sides in prone position.

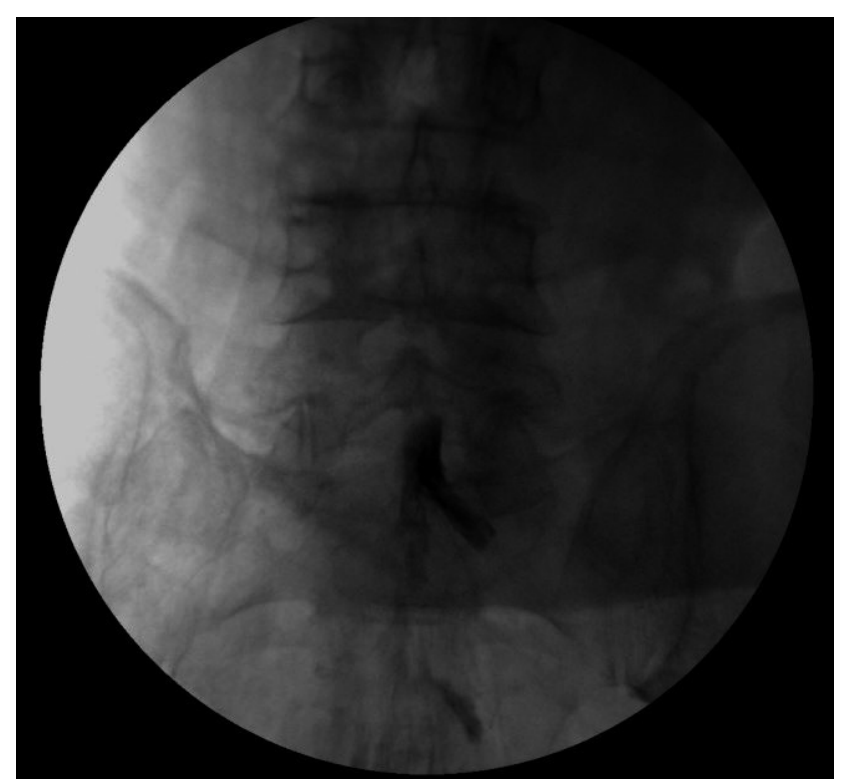

Fig. 3. Image demonstrating the injectate accumulates at the bottom in lateral decubitus position.

minute $(\mathrm{p}=0.002)$, 3rd week $(p<0.001)$, 3rd month $(p=0.006)$ and 12th month $(p=0.014)$. No difference was noted between two groups in terms of WT and ST at any of the intervals.

Table 2 displays the alteration of parameters in both groups
Table 1. Comparative overview of descriptive and clinical parameters in two groups

\begin{tabular}{|c|c|c|c|c|}
\hline Variable & Interval & Group 1 & Group 2 & $p$-value \\
\hline \multirow[t]{6}{*}{$\mathrm{ODI}^{\dagger}$} & Initial & $35.4 \pm 3.7$ & $35.4 \pm 3.8$ & 0.923 \\
\hline & 30th minute & $23.0 \pm 3.2$ & $21.6 \pm 2.5$ & $0.007^{*}$ \\
\hline & 3rd week & $23.0 \pm 2.5$ & $22.2 \pm 2.2$ & $0.043^{*}$ \\
\hline & 3rd month & $23.1 \pm 2.6$ & $22.8 \pm 2.5$ & 0.545 \\
\hline & 6th month & $24.2 \pm 2.1$ & $23.1 \pm 2.3$ & $0.013^{*}$ \\
\hline & 12th month & $24.4 \pm 2.5$ & $24.3 \pm 2.8$ & 0.838 \\
\hline \multirow[t]{6}{*}{$\mathrm{NRS}^{\ddagger}$} & Initial & $8.0-1.0$ & $8.0-1.0$ & 0.821 \\
\hline & 30th minute & $4.0-1.0$ & $4.0-1.0$ & $0.002^{*}$ \\
\hline & 3rd week & $4.0-1.0$ & $4.0-1.0$ & $<0.001^{*}$ \\
\hline & 3rd month & $4.0-1.0$ & $4.0-1.0$ & $0.006^{*}$ \\
\hline & 6th month & $4.0-1.0$ & $4.0-1.0$ & 0.136 \\
\hline & 12th month & $5.0-1.0$ & $4.0-1.0$ & $0.014^{*}$ \\
\hline \multirow[t]{6}{*}{$\mathrm{ST}^{\ddagger}$} & Initial & $1.0-0.8$ & $1.0-1.0$ & 0.681 \\
\hline & 30th minute & $2.0-1.0$ & $2.0-1.0$ & 0.324 \\
\hline & 3rd week & $2.0-1.0$ & $2.0-1.0$ & 0.379 \\
\hline & 3rd month & $2.0-1.0$ & $2.0-1.0$ & 0.729 \\
\hline & 6th month & $2.0-1.0$ & $2.0-1.0$ & 1.000 \\
\hline & 12th month & $2.0-1.0$ & $1.5-1.0$ & 0.790 \\
\hline \multirow[t]{6}{*}{$W T^{\ddagger}$} & Initial & $1.0-1.0$ & $1.0-1.0$ & 0.696 \\
\hline & 30th minute & $2.0-1.0$ & $2.0-1.0$ & 0.684 \\
\hline & 3rd week & $2.0-1.0$ & $2.0-1.0$ & 0.732 \\
\hline & 3rd month & $2.0-1.0$ & $2.0-1.0$ & 0.386 \\
\hline & 6th month & $1.0-1.0$ & $1.0-1.0$ & 1.000 \\
\hline & 12th month & $1.0-1.0$ & $1.0-1.0$ & 0.715 \\
\hline
\end{tabular}

*Statistically significant. ${ }^{\dagger}$ expressed in mean \pm standard deviation. ${ }^{\ddagger}$ Expressed as median-interquartile range. ODI : Oswestry disability index, NRS : numeric rating scale, ST : standing tolerance, WT: walking tolerance

after caudal epidural injection. In Group 1, ODI, NRS and ST values were improved significantly at all follow-up periods compared to initial values. In Group 1, WT scores were better than initial values at 30 th minute $(p<0.001)$, 3 rd week $(p<0.001)$ and 3rd month $(p=0.009)$. In Group 2, ODI scores at 30th minute $(p=0.005)$, 3rd week ( $p=0.001)$, 3rd month $(p<0.001)$ and 6th month $(p<0.001)$ were better than initial ODI values. At all periods after injection, NRS and ST scores were improved notably in Group 2. However, WT scores were better at 30th minute $(p<0.001)$, 3rd week $(p=0.001)$ and 3 rd month $(p=0.002)$ compared to initial WT scores. 
Table 2. Comparison of alterations of parameters under investigation during study period within each group

\begin{tabular}{|c|c|c|c|c|}
\hline \multirow{2}{*}{ Parameter } & & \multirow{2}{*}{ Interval } & \multicolumn{2}{|c|}{$p$-value } \\
\hline & & & Group 1 & Group 2 \\
\hline \multirow[t]{5}{*}{ ODI } & Initial & 30th minute & $0.002^{*}$ & $0.005^{*}$ \\
\hline & & 3rd week & $<0.001^{*}$ & $0.001^{*}$ \\
\hline & & 3rd month & $<0.001^{*}$ & $<0.001^{*}$ \\
\hline & & 6th month & $0.007^{*}$ & $<0.001^{*}$ \\
\hline & & 12th month & $0.001^{*}$ & 0.135 \\
\hline \multirow[t]{5}{*}{ NRS } & Initial & 30th minute & $<0.001^{*}$ & $<0.001^{*}$ \\
\hline & & 3rd week & $<0.001^{*}$ & $<0.001^{*}$ \\
\hline & & 3rd month & $<0.001^{*}$ & $<0.001^{*}$ \\
\hline & & 6th month & $<0.001^{*}$ & $<0.001^{*}$ \\
\hline & & 12th month & $<0.001^{*}$ & $<0.001^{*}$ \\
\hline \multirow[t]{5}{*}{ ST } & Initial & 30th minute & $<0.001^{*}$ & $<0.001^{*}$ \\
\hline & & 3rd week & $<0.001^{*}$ & $<0.001^{*}$ \\
\hline & & 3rd month & $<0.001^{*}$ & $<0.001^{*}$ \\
\hline & & 6th month & $<0.001^{*}$ & $<0.001^{*}$ \\
\hline & & 12th month & $<0.001^{*}$ & $0.002^{*}$ \\
\hline \multirow[t]{5}{*}{ WT } & Initial & 30th minute & $<0.001^{*}$ & $<0.001^{*}$ \\
\hline & & 3rd week & $<0.001^{*}$ & $0.001^{*}$ \\
\hline & & 3rd month & $0.009^{*}$ & $0.002^{*}$ \\
\hline & & 6th month & 0.067 & 0.142 \\
\hline & & 12th month & 0.473 & 0.442 \\
\hline
\end{tabular}

*Statistically significant. ODI : Oswestry disability index, NRS : numeric rating scale, ST : standing tolerance, WT : walking tolerance

\section{DISCUSSION}

In this study, we attempted to assess and compare the efficacies of caudal epidural injection at prone and lateral decubitus positions for patients suffering from low back pain and radicular leg pain associated with CSS and LDH. Our results demonstrated that performance of injection at lateral decubitus position may relieve the pain more effectively and this may be due to a more concentrated local distribution of injectate at this position.

Contemporarily, caudal epidural injections are commonly used in the management of chronic low back pain associated with radicular leg pain and their results are reported as variable. Positioning of the patient may enhance anesthetic application owing to the principle that hyperbaric to cerebrospinal fluid accumulate on the dependent side because of the effect of gravity ${ }^{3,15)}$. Sumi et al. suggested that maintaining a patient in lateral decubitus position for 20 minutes after spinal anesthesia provided a preferential distribution of anesthetic solution onto the dependent side ${ }^{15)}$.

Positioning of patient during and after injection may improve the efficacy of caudal epidural injection. Importance of positioning after caudal epidural injection had been previously investigated ${ }^{8}$. Since injectate used in this purpose is hyperdense, it may accumulate on the dependent side after injection owing to the effect of gravity. Therefore, laying a patient on the side of leg pain after injection may be more useful for a better relief of pain ${ }^{11)}$.

In selective spinal anesthesia (SSA), minimal doses of intrathecal agents are used, so that only the nerve roots supplying a specific area and only the modalities that require to be anesthetized are affected $^{7}$. The aim of producing a reliable SSA for outpatients stresses the importance of understanding the factors affecting the spread of spinal anesthesia ${ }^{7,16)}$. Enk $^{5)}$ has pointed out the significance of the 'low-dose, low-volume and low-flow' technique for achieving unilateral block. Maintenance of the lateral decubitus position for 5-30 min has been shown to be important ${ }^{5}$.

As far as we know, this is the first trial to evaluate the impact of position during injection. Our results yielded that administration of caudal epidural injection at lateral decubitus position provided a more effective relief of pain and a better functional improvement compared to injection made at prone position. Injections performed at lateral decubitus position seems to provide better functional scores as reflected in ODI scores and seems to relieve pain more effectively as reflected in NRS. Long duration of follow-up in our series offers another advantage in terms of reliability of our results and we hope that data derived from the present study will aid in development of newer techniques. Even though majority of similar studies have kept the follow-up period to 6 weeks, we extended this interval up to 12 months and this aspect is another superiority of the current study. Proper positioning during caudal epidural injection is a safe, practical and cost-effective maneuver that amplifies the efficacy of the procedure. Since no adverse effects or hazards have been observed with positioning, we suggest that this option must be remembered during routine injection interventions.

The spread of the injectate distal to the site of injection may vary due to the speed and the amount of local anesthetic solution. Further studies are warranted to determine the optimum 
doses of local anesthetics and speed of the injection in caudal epidural injection method. Second, clinical evaluation focusing on other domains of life such as general health and quality of life needs to be addressed in further trials. Third, since additional co-morbidities may influence the outcomes in terms of pain and function in various age groups, effectivity of the procedure should be investigated separately in distinct demographic groups ${ }^{12}$.

Limitations of the present study consist of small sample size and lack of definite criteria for selection of patients for this method. In addition, ethnic, environmental and genetic factors likely to affect the therapeutic outcomes and subjective indicators of pain and function could not be completely controlled. This data reflects the experience of a single institution and personal variations and technical restrictions may affect the sensitivity to pain and response to treatment considerably. A placebo arm was not established due to ethical considerations, however, spontaneous improvement may have occurred and it may explain the results as well.

\section{CONCLUSION}

To conclude, results of the current study have demonstrated that selection of position during application of caudal epidural injection must be made with respect to distribution of drug according to the effect of gravity.

\section{References}

1. Abdi S, Datta S, Trescot AM, Schultz DM, Adlaka R, Atluri SL, et al. : Epidural steroids in the management of chronic spinal pain : a systematic review. Pain Physician 10 : 185-212, 2007

2. Alderman N, Shepherd J, Youngson $\mathrm{H}$ : Increasing standing tolerance and posture quality following severe brain injury using a behavior modification approach. Physiotherapy 78 : 335-343, 1992

3. Botwin K, Brown LA, Fishman M, Rao S : Fluoroscopically guided caudal epidural steroid injections in degenerative lumbar spine stenosis. Pain

\section{Physician 10 : 547-558, 2007}

4. Dincer U, Kiralp MZ, Cakar E, Yasar E, Dursan H : Caudal epidural injection versus non-steroidal anti-inflammatory drugs in the treatment of low back pain accompanied with radicular pain. Joint Bone Spine $\mathbf{7 4}$ : 467-471, 2007

5. Enk D : Unilateral spinal anaesthesia : gadget or tool? Curr Opin Anaesthesiol $11:$ 511-515, 1998

6. Fairbank JC, Pynsent PB : The Oswestry disability index. Spine (Phila Pa 1976) 25 : 2940-2952; discussion 2952, 2000

7. Korhonen AM, Valanne JV, Jokela RM, Ravaska P, Volmanen P, Korttila K : Influence of the injection site (L2/3 or L3/4) and the posture of the vertebral column on selective spinal anesthesia for ambulatory knee arthroscopy. Acta Anaesthesiol Scand 49 : 72-77, 2005

8. Makki D, Nawabi DH, Francis R, Hamed AR, Hussein AA : Is the outcome of caudal epidural injections affected by patient positioning? Spine (Phila Pa 1976) 35 : E687-E690, 2010

9. Manchikanti L, Singh V, Cash KA, Pampati V, Damron KS, Boswell MV : Preliminary results of a randomized, equivalence trial of fluoroscopic caudal epidural injections in managing chronic low back pain : Part 2-Disc herniation and radiculitis. Pain Physician 11 : 801-815, 2008

10. Mannion AF, Balagué $F$, Pellisé $F$, Cedraschi $C$ : Pain measurement in patients with low back pain. Nat Clin Pract Rheumatol 3 : 610-618, 2007

11. Martin-Salvaj G, Van Gessel E, Forster A, Schweizer A, Iselin-Chaves I, Gamulin Z : Influence of duration of lateral decubitus on the spread of hyperbaric tetracaine during spinal anesthesia : a prospective time-response study. Anesth Analg 79 : 1107-1112, 1994

12. Miyakoshi N, Shimada Y, Kasukawa Y, Saito H, Kodama H, Itoi E : Total dorsal ramus block for the treatment of chronic low back pain : a preliminary study. Joint Bone Spine 74 : 270-274, 2007

13. Ritti-Dias RM, Wolosker $\mathrm{N}$, de Moraes Forjaz $\mathrm{CL}$, Carvalho $\mathrm{CR}$, Cucato GG, Leão PP, et al. : Strength training increases walking tolerance in intermittent claudication patients : randomized trial. J Vasc Surg 51 : 89-95, 2010

14. Schizas C, Theumann N, Burn A, Tansey R, Wardlaw D, Smith FW, et al. : Qualitative grading of severity of lumbar spinal stenosis based on the morphology of the dural sac on magnetic resonance images. Spine (Phila Pa 1976) 35 : 1919-1924, 2010

15. Sumi M, Sakura S, Koshizaki M, Saito Y, Kosaka Y : The advantages of the lateral decubitus position after spinal anesthesia with hyperbaric tetracaine. Anesth Analg 87 : 879-884, 1998

16. Vaghadia $H$ : Spinal anaesthesia for outpatients : controversies and new techniques. Can J Anaesth 45(5 Pt 2) : R64-R75, 1998 